\title{
AN IN VITRO STUDY ON THE ANTI-ADHERENCE PROPERTIES OF MOUTHRINSES CONTAINING CHLORHEXIDINE GLUCONATE AND HEXITIDINE
}

Fathilah A.R., Othman Y. and Rahim Z.H.A. An in vitro study on the anti-adherence properties of mouthrinses containing chlorhexidine gluconate and hexitidine. Annal Dent Univ Malaya 1999; 6: 17 - 20.

\begin{abstract}
Chlorhexidine gluconate and hexitidine have been used in many oral health care products as antiplaque and antigingivitis agents. Based on the clinical observations and the plaque and gingivitis scores, chlorhexidine gluconate has been reported to be a better agent. In this study, the anti-adherence properties of chlorhexidine gluconate and hexitidine on individual bacteria strains isolated from a 3-hour plaque (Streptococcus sanguis, Streptococcus mitis 1 and Actinomyces sp.) and on a whole 6-hour plaque culture were determined and compared. The study showed that chlorhexidine gluconate inhibited almost $100 \%$ the adherence of the individual bacteria strains and $87.7 \%$ the adherence of a whole 6 -hour plaque culture to the saliva-coated glass surface. Hexitidine appeared to be more selective in its effect. It was shown to inhibit the adherence of S. sanguis and Actinomyces sp. to saliva-coated glass surface by $86.5 \%$ and $51.4 \%$ respectively. Its effect on the $S$. mitis 1 strains is comparable to that of a whole 6-hour plaque culture where inhibition to adherence were less than $4 \%$ for both.
\end{abstract}

Keywords: Chlorhexidine gluconate; hexitidine; adherence; affinity; anti-adherence

\section{INTRODUCTION}

The increasing awareness of plaque as a major contributing factor in the initiation of caries and periodontal disease has changed the perception of consumers on the role of mouthrinses in keeping the oral cavity clean. Listerine, Chlorhexidine, Plax, Bactidol and many other commercially available products which has long been accepted as breath freshener and antiseptics, are now expected to also play a role as antiplaque agent.

Chlorhexidine gluconate has been accepted as the most effective agent in reducing plaque and preventing gingivitis (1). Studies on chlorhexidine has been tremendous eversince its antiplaque property was reported (2). Hexitidine is another active component of several oral health care products. However with only $40 \%$ reduction in the total plaque index (3), hexitidine is less effective and thus less studied as compared to chlorhexidine which normally showed a reduction within the range of $60 \%$ (4).

Many studies on chemical plaque control have been carried out $(1,5,6)$ with several different approaches to the problem. These included those that affect plaque removal and those that prevent plaque formation. Although studies on both agents have been great, the approach to their effect was mainly clinical, with results represented in

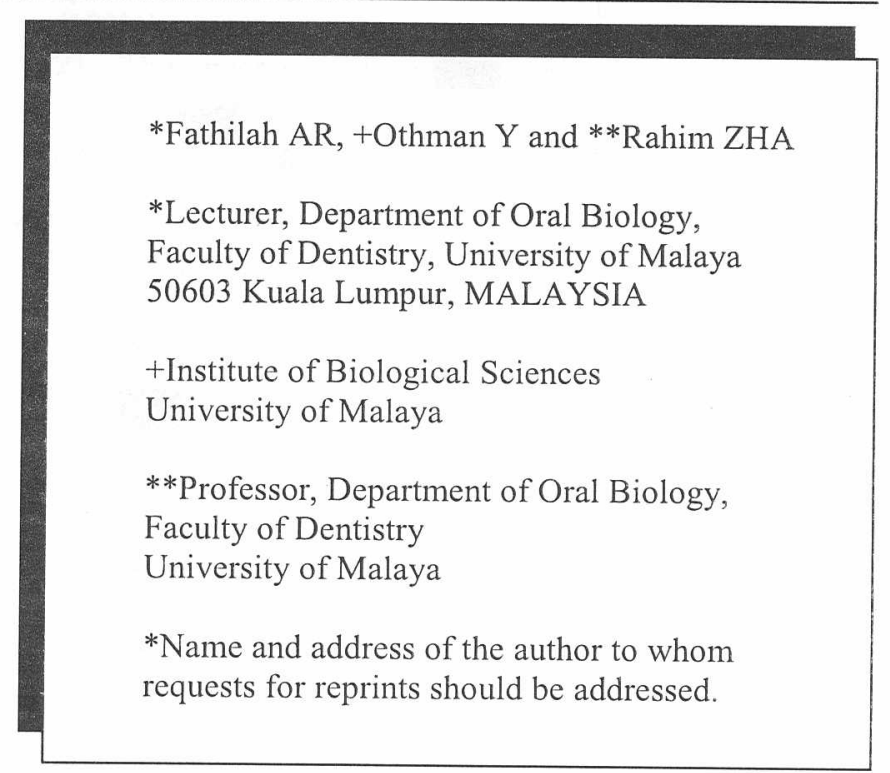

terms of plaque and gingivitis indices. Determining the effect of antiplaque agents on the attachment of bacteria on the tooth surfaces can be an alternative approach to the study of their antimicrobial effect on dental plaque.

Saliva-coated glass surface can be used to simulate the pellicle-coated enamel surface in the oral cavity. Glass surface has been reported to be equally satisfactory as an adherence surface compared to that of hydroxyapatite or an enamel surface. The anti-adherence effect can then be determined by the difference in the binding capacity to the glass surface between the salivacoated glass tubes with the saliva-coated glass tubes treated with the antiplaque agents.

In this study, the anti-adherence properties of chlorhexidine gluconate and hexitidine on individual bacteria strains isolated from a 3-hour plaque ( $S$. sanguis, S. mitis 1, Actinomyces sp.) as well as on a whole 6-hour plaque culture were determined and compared.

\section{MATERIALS AND METHODS \\ Materials \\ Commercial mouthrinse}

Mouthrinse-A containing chlorhexidine gluconate $0.12 \%$ and mouthrinse-B containing hexitidine $0.1 \%$ were purchased from the local pharmacy.

\section{Bacterial strains}

S. sanguis, $S$. mitis 1, Actinomyces sp. were isolated from a 3-hour supragingival plaque. The 3-hour and a 6-hour supragingival plaque were obtained from one and the same subject.

\section{Growth media}

Schaedler anaerobic broth and Schaedler anaerobic agar were purchased from OXOID, Unipath Ltd., Basingstoke, Hampshire, England. 
Figure 1: In vitro assay method to measure the adherence of plaque bacteria to saliv a-coated glass surfaces. (1) Saliva-coated glass tube; (2) Addition of $2 \mathrm{ml}$ bacterial suspension; ( $3 \& 4$ ) The sum of both readings represent turbidity of free unbound cells; (5) Turbidity of adherent cells.

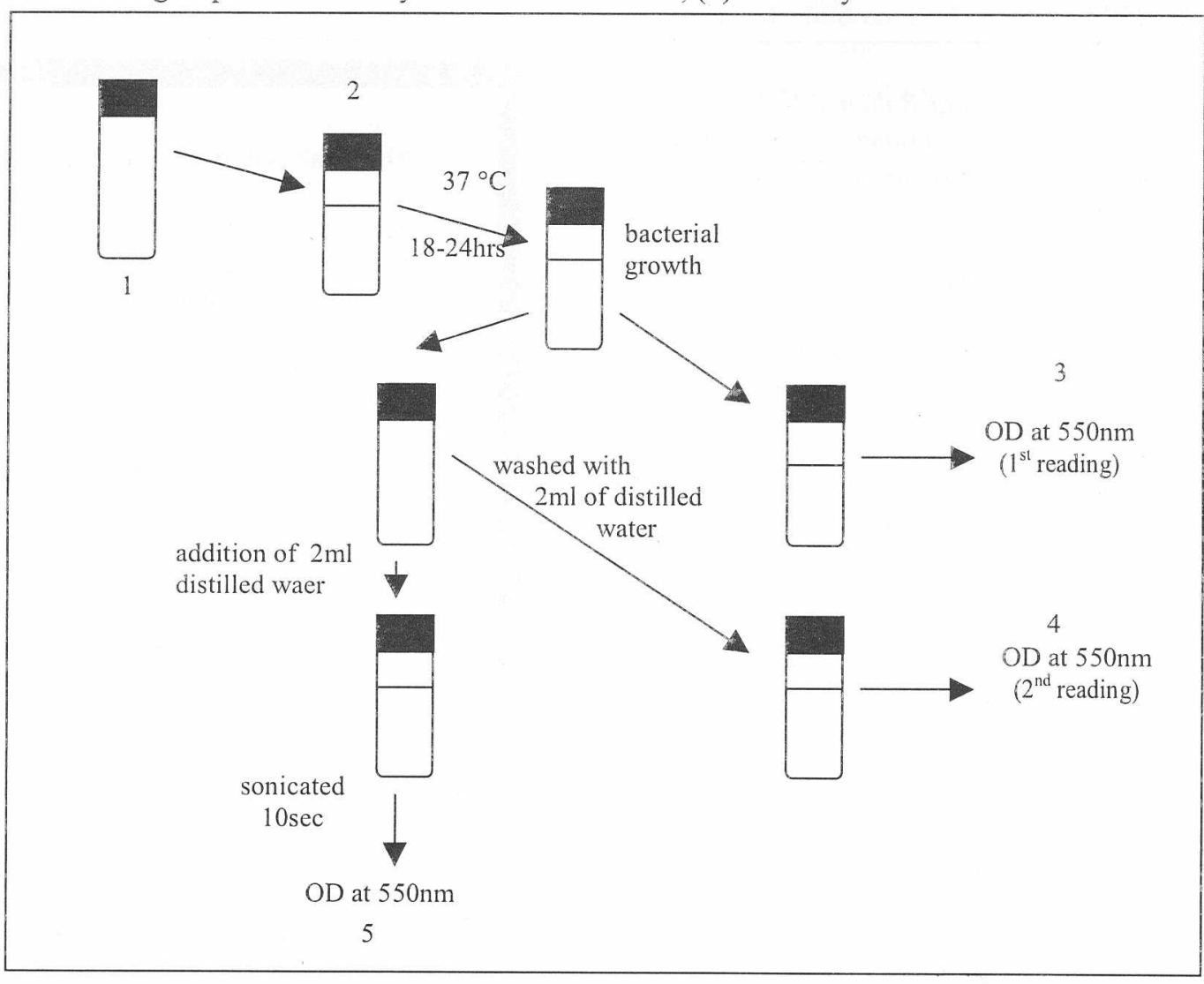

\section{Methods}

\section{Preparation of cultures and bacterial suspension}

$S$. sanguis, $S$. mitis 1 and Actinomyces sp. from a 3 -hour plaque samples which have been kept in glycerol as stocks at $-70{ }^{\circ} \mathrm{C}$ were isolated and identi fied using the method of Wollinsky et al (7). The stocks were th awed, inoculated onto an anaerobic agar plate and in cubated at $37^{\circ} \mathrm{C}$ for 18 20 hours. The colonies were then harvested and dispersed into a $30 \mathrm{ml}$ anaerobic broth containing $5 \%(\mathrm{w} / \mathrm{v})$ sucrose. For a whole 6-hour plaque culture, the 6-hour plaque samples were incubated in a $30 \mathrm{ml}$ anaerobic broth containing $5 \%(\mathrm{w} / \mathrm{v})$ sucrose. The turbidity of the suspension of the individual bacteria strains and that of whole plaque culture was adjusted spectrophotometrically in cuvettes $\left(O_{550 \mathrm{~mm}}\right)$ to about 0.144 for use in the adherence assay.

\section{Collection of saliva}

Whole saliva (WS) was collected into ice-chilled tubes from a single donor by expectoration after chewing a piece of rubber band. The WS was clarified by centrifugation $(17,000 \mathrm{~g}, 30 \mathrm{~min})$ prior to storing at $-20^{\circ} \mathrm{C}$ for further analysis.

\section{Determination of the anti-adherence property}

The study was carried out us ing three se ts of gl ass tubes, one control and two test groups:

1. Glass tube 1: Saliva-coated glass surface which served as control.
2. Glass tube 2: Saliva-coated glass surface and treated with mouthrinse-A

3. Glass tube 3: Saliva-coated glass surface and treated with mouthrinse-B

Preparation of saliva-coated glass tubes

Saliva-coated glass tubes were prepare $\mathrm{d}$ by exposing the glass walls to clarified saliva for 2 minutes and later briefly rinsed with sterile distilled water. These glass tubes represented the untreated and control.

\section{Preparation of mouthrinse-coated glass tubes}

Mouthrinse-coated glass tubes were prepared by re-coating the saliva-coated glass tubes with mouthrinse-A for 2 minutes. Following the trea tment, the tubes were briefly rinsed with sterile distilled water. Similar treatment procedure was also done using mouthrinse-B.

In vitro anti-adherence assay

To each of the glass tubes; saliva-coated, mouthrinse-Acoated, and mouthrinse-B-coated glass tubes, $2 \mathrm{ml}$ of bacterial suspension was added followed by incubati on at $37^{\circ} \mathrm{C}$ for $18-20$ hours. Bacterial suspensions used were $S$. sanguis, $S$. mitis 1, Actinomyces sp. and a whole 6-hour plaque culture.

Following incubation, the growth suspension was transferred into fresh glass tubes and the turbidity of the suspension containing the free bacteria 1 cells were measured spectrophotometrically at $550 \mathrm{~nm}$ (first reading). 
The bacterial cells adhering to the glass tubes were rinsed with $2 \mathrm{ml}$ of sterile distilled water to rinse out the nonadherent bacterial cells. The washes were collected into fresh glass tubes and the turbidity of the non-adherent cells was measured at $550 \mathrm{~nm}$ (second reading). $2 \mathrm{ml}$ of fresh sterile distilled water was added to the emptied tubes containing the adherent bacteria. The glass tubes were sonicated for $10 \mathrm{sec}$ to detach the adherent bacterial cells and the turbidity of the suspension containing the adherent bacterial cells was then read spectrophotometrically at $550 \mathrm{~nm}$. The experiment was carried out in duplicates. A diagrammatic representation of the assay method is shown in Figure 1.

The turbidity of the suspensions obtained following sonication of the glass tubes will represent the concentration of the adherent bacterial cells while the sum of the first and second readings represent the concentration of the non-adherent bacteria. The adherence affinity can be defined as the percentage of the bacterial cells which adhere or bound to the glass surface. In this study, the maximum population of cells that can bind to glass surface is represented by the cells that adhere to the saliva-coated glass surface. The effects of the mouthrinses $A$ and $B$ on adherence of the bacterial cells to the saliva-coated glass surface will determine their anti-adherence property. Therefore the anti-adherence property will be expressed by the difference between the adherence affinity to salivacoated glass surface in the absence of the antiplaque agents and those in the presence of the agents.

\section{RESULTS}

Adherence affinities to saliva-coated glass surface

The three early colonizers ( $S$. mitis $1, S$. sanguis and Actinomyces sp.) of dental plaque studied individually showed to have varying adherence affinities to salivacoated glass surface. Actinomyces sp. appeared to have the highest adherence affinity at $32.5 \%$ followed by $S$. mitis 1 and $S$. sanguis which showed equal affinity at $22.7 \%$ and $22.1 \%$ respectively. The whole 6-hour plaque culture however, exhibited the least adherence affinity at $13.7 \%$ as compared to those of the early colonizers (Figure 2).
Adherence affinities to saliva-coated glass surface treated with mouthrinse-A

The adherence of S. sanguis, S. mitis 1 and Actinomyces $\mathrm{sp}$. to saliva-coated glass surface were almost totally $(100 \%)$ inhibited in the presence of mouthrinse-A (Figure 2). The adherence of the whole 6-hour plaque culture was also greatly reduced $(87.7 \%)$ as compared to the adherence to saliva-coated glass surface in the absence of mouthrinse-A (Table 1).

Adherence affinities to saliva-coated glass surface treated with mouthrinse- $B$

The adherence properties of both $S$. sanguis and Actinomyces sp. were dramatically reduced $(86.5 \%$ and $51.4 \%$ respectively) as compared to the control (salivacoated glass surface without mouthrinses) when mouthrinse-B was used to coat the saliva-coated glass surface. Mouthrinse-B showed a very mild effect $(<4 \%)$ towards both $S$. mitis 1 and the whole 6-hour plaque culture.

Table 1: Anti-adherence effect of mouthrinse-A and mouthrinse-B on S. mitis 1, S. sanguis, Actinomyces sp. and whole plaque culture given in percentage as compared to their adherence affinity to saliva-coated glass surface.

\begin{tabular}{|l|c|c|}
\hline \multirow{2}{*}{ Bacteria tested } & \multicolumn{2}{|c|}{ Inhibition of Adherence (\%) } \\
\cline { 2 - 3 } & Mouthrinse A & Mouthrinse B \\
\hline S. mitis 1 & $\sim 100$ & $<4$ \\
\hline S. sanguis & $\sim 100$ & 86.5 \\
\hline Actinomyces sp. & $\sim 100$ & 51.4 \\
\hline Whole plaque & 87.7 & $<4$ \\
\hline
\end{tabular}

Figure 2: Percentage of adherent bacterial cells to saliva-coated glass surface after treatment with mouthrinses- $\mathrm{A}$ and $-\mathrm{B}$ as compared to that without treatment

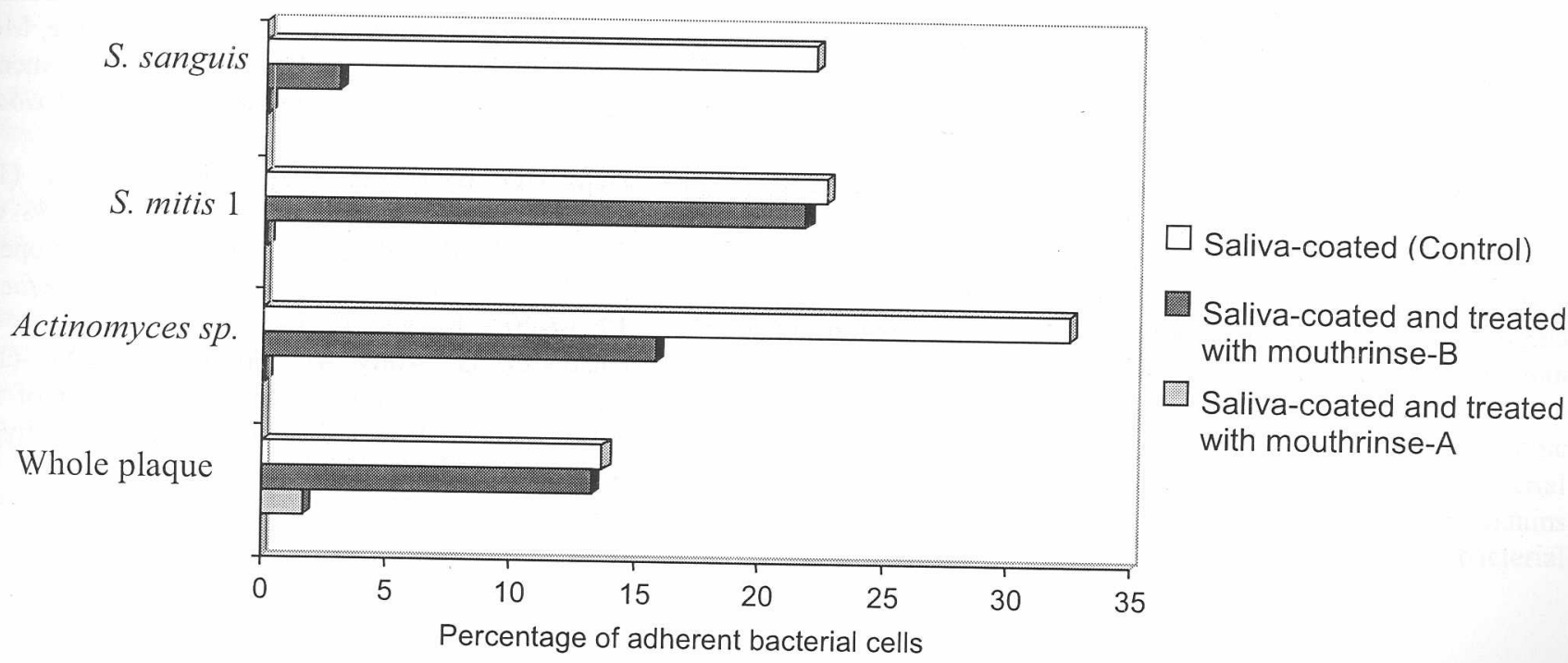




\section{DISCUSSION}

Adhesion of bacterial cells onto saliva-coated glass surface is the first step towards the formation of plaque. According to Lee et al, (8), the adherence stage occurred very quickly ( $0-1$ hour) as a result of the attachment of planktonic cells to the surface. The adhered cells will then began to divide while more planktonic cells continued to adhere to the surface. Cell growth following these two initial events contributes to further development of plaque biofilm onto the surface. In this adherence study, glass surface was used since it has been shown to be equally satisfactory as an adherence model compared to hydroxyapatite or an enamel surface (9).

Chlorhexidine gluconate is a compound with a very broad antimicrobial spectrum and have the ability to bind to both soft and hard tissues surfaces. This property enables it to act over a long period after used. The potency of chlorhexidine gluconate as an antimicrobial compound has been well established $(1,4,10,11,12,13)$. In this study, chlorhexidine gluconate was shown to inhibit almost 100\% the adherence of $S$. mitis 1 , S. sanguis and Actinomyces sp. to saliva-coated glass surfaces and $87.7 \%$ the adherence of whole plaque culture (Table 1). Thus, the inhibition of adherence of the bacteria strains in a whole 6-hour plaque culture was reduced by $12.3 \%$ as compared to its effect on the individual bacteria strains.

The anti-adherence effect of hexitidine on the other hand appears to be more selective over certain bacteria strains. Individually, the adherence of $S$. sanguis and Actinomyces sp. were more affected by the compound as compared to $S$. mitis 1 (Table 1). The inhibition of the adhesion was $86.7 \%$ and $51.4 \%$ for $S$. sanguis and Actinomyces sp. respectively. The adherence of whole plaque culture and $S$. mitis 1 however, was shown to be resistant and not affected by hexitidine where the inhibition of adherence was less than $4 \%$ for both. This result could explain why hexitidine has been shown to be less effective as an antimicrobial agent (14).

\section{CONCLUSION}

Oral bacteria adhered to saliva-coated glass surfaces with different capacity. The adherence of individual bacteria strains like $S$. mitis $1, S$. sanguis and Actinomyces sp. was shown to be inhibited almost completely by chlorhexidine gluconate. S. sanguis and Actinomyces sp. were shown to adhere less in the presence of hexitidine (86.5\% and 51.4\% respectively). The adherence of $S$. mitis 1 was not greatly affected by hexitidine $(<4 \%)$.

When the bacteria strains are present together as in a whole plaque culture, chlorhexidine gluconate has a greater anti-adherence activity $(87.7 \%)$ as compared to hexitidine $(<4 \%)$. It does appear that chlorhexidine gluconate has a better anti-adherence property as compared to hexitidine both on individual bacteria strain and whole plaque culture.

\section{REFERENCES}

1. Adams D and Addy M. (1994). Mouthrinses. Adv Dent Res 8(2): 291-301.

2. Loe H, and Schiott CR. (1970) The effects of suppression of the oral microflora upon the development of dental plaque and gingivitis. In: McHugh WD, editor. Dental plaque. Edingurgh. E \& S Livingston, 247-255.

3. Williams MJR, Adams D, Hillam DG and Ashley $\mathrm{KC}$. (1987). The effect of hexitidine $0.1 \%$ in the control of dental plaque. Br Dent J 163: 300-302.

4. Grossman E, Reiter GP, Sturzenberger OP, de la Rosa M, Dickinson TD and Ferreti GA. (1986). Six month study of the effects of a chlorhexidine mouthrinse on gingivitis in adults. $J$ Periodont Res 21: 33-43.

5. Addy M. (1986). Chlorhexidine compared with other locally delivered antimicrobial. A short review. J Clin Periodontol 13: 957-964.

6. Mandel ID. (1988). Chemotherapeutic agents for controlling plaque and gingivitis. $J$ Clin Periodontol 15: 488-498.

7. Wollinsky LE, Mania S, Nachnani S and Ling S. (1996). The inhibiting effect of aqueous Azadirachta indica (Neem) extract upon bacterial properties influencing in vitro plaque formation. $J$ Dent Res 75(2): 816-822.

8. Lee SF, Li YH and Bowden GH. (1996). Detachment of Streptococcus mutans biofilm cells by an endogenous enzymatic activity. Infection and Immunity 64(3): 1035-1038.

9. Ciardi JE, Rosenthal AB and Bowden WH. (1981). Rapid quantitative determination of the effect of antiplaque agents and antisera on the growth, acid production and adherence of Streptococccus mutans. $J$ Dent Res 60(3): 756-762.

10. Addy M, Moran J, Griffiths A, Wills-Wood NJ (1985). Extrinsic tooth discoloration by metals and chlorhexidine. 1: Surface protein denaturation or dietary precipitation? Br Dent $J$ 159: 331-334.

11. Addy M, Wade WG, Jenkins $\mathrm{S}$ and Goodfield S. (1989) Comparison of 2 commercially available chlorhexidine mouthrinses: 1 Staining and antimicrobial effects in vitro. Clin Prev Dent 11(5): 10-14.

12. Brecx M, Brownstone E, MacDonald L, Gelskey S and Cheang M. (1992). Efficacy of Listerine, Meridol and chlorhexidine mouthrinses as supplements to regular tooth cleaning measures. $J$ Clin Periodontol 19: 202-207.

13. Heps HU, Bjornland $\mathrm{T}$ and Skoglund LA. (1988). Side-effects and patient acceptance of $0.2 \%$ versus $0.1 \%$ chlorhexidine used as post-operative prophylactic mouthwash. Int J Oral Maxillofac Surg 17: 17-20.

14. Chadwick B, Addy $M$ and Walker DM. (1991). Hexitidine mouthrinse in the management of minor aphthous ulceration and as an adjunct to oral hygiene. Br Dent J 171:83-87. 